\title{
INDUCTION OF LABOUR BY INTRAVAGINAL MISOPROSTOL IN INTRA UTERINE DEATH OF FETUS AT SSMC AND MITFORD HOSPITAL, DHAKA
}

\author{
AFROZ ${ }^{1}$, ANWAR BR ${ }^{2}$, KHANOM A ${ }^{1}$, BISWAS PK ${ }^{3}$, ISLAM $\mathrm{S}^{4}$, ROUF R
}

\begin{abstract}
Intra uterine fetal death occur in 1\% of pregnancy. The patient goes into labour in most of the cases, spontaneously. Retained dead fetus may cause disseminated intravascular coagulation sometimes resulting death of a mother. Objective: The aim was to find out the reults after using intravaginal Misoprostol in Intrauterine fetal death in last trimester of pregnancy.

Study design: This was a cross sectional observational study prospective in nature on 160 cases of intra uterine fetal death patients in indoor of department of Gynae and Obstertrics of Sir Salimullah medical college Hospital, Dhaka from 02/01/ 13 to 01/07/13, for a period of 6 months.

Result: $60 \%$ of the patients were primi gravida. Mean age of the patients was $22.12 \pm 4.3$ years 44\% were in 33 to 36 weeks of pregnancy when induction was done. 41 (82\%) patients having Bishops score d" 6 reqired $21 \pm 8.25$ hours where as 09 (18\%) patients having Bishops score e" 6 needed $10 \pm 1,1$ hours to complete the delivery. There were no reports of maternal mortality. All the patients delivered per vaginally except one (2\%) who needed ceasearean section due to development of chorioamnionitis.
\end{abstract}

Conclusion: Intravaginal misoprostol can aid in vaginal delivery safely.

J Dhaka Med Coll.2019; 28(1) : 90-93

\section{Introduction:}

Stillbirth is one of the most common adverse outcomes of pregnancy, with an estimated rate of 5.3 per 1000 deliveries in developed countries; the rate is about fivefold higher $(25.5$ per 1000 deliveries) in developing countries. ${ }^{1}$ In one study in Bangladesh the stillbirth rate was 26 per 1000 total births, of which $62 \%$ occurred during the intrapartum period. ${ }^{2}$ Obstetrical complications contributed to $61.4 \%$ of stillbirths. ${ }^{2}$ Current practice is to induce labour earlier both because many women do not wish the dead fetus to remain in utero for weeks and because of the possibility of developing of coagulopathy. Induction of labour in intra uterine fetal death should always be done by medical induction. The ideal induction method for third-trimester stillbirth has not been determined. Stillbirth, defined as fetal death at 20 weeks or more of gestation, is a common adverse out come of pregnancy. ${ }^{3}$
Usually in $80 \%$ cases spontaneous expulsion occurs within two weeks of death. But early termination is favoured considering the psychological upset of the patient in carrying the dead fetus within her uterus for long period and there is also a remote chance of DIC.

Management of stillbirth is based on gestational age, suspected etiology, maternal history of previous uterine scars, and maternal wishes ${ }^{4}$ Care should be individualized and involve the woman and her family in the decision-making process. ${ }^{5}$ Misoprostol, a prostaglandinE1 analogue, marketed as a cytoprotective agent is safe, efficacious and inexpensive for use in cervical ripening and labour induction. ${ }^{6}$.Most clinical trial used 25-100 $\mu$ gm prepared from oral tablets and inserted intravaginally. ${ }^{7}$

Aim of this study was to find out the result after vaginal application of prostaglandin for induction of labour (IOL) in IUFD.

1. Dr. Mahenaz Afroz, Dr. Afroza Khanom, Assistant Professor, Department of Gynae-oncology, NICRH, Dhaka.

2. Dr. Begum Rokeya Anwar, Associate Professor, Department of Gynae-oncology, NICRH, Dhaka

3. Dr. Prodip Kumar Biswas, Associate Professor, Department of Medicine, DMCH, Dhaka .

4. Dr. Sadia Islam, Assistant Professor of Medicine, Delta Medical College \& Hospital, Dhaka

5. Dr. Rozana Rouf, Specialist, Department of Medicine, Square Hospital, Dhaka

Address of Correspondence: Dr. Mahenaz Afroz Assistant Professor, Department of Gynae-oncology, NICRH, Dhaka. 


\section{Materials and Method}

This is a prospective study, being carried out from July 2008 to 30th June 2009 in the department of obstetrics and gynaecology, SSMC and Mitford Hospital. The cases were selected from patients with intra uterine fetal death who were primi or multigravida within the gestational age of 28 weeks to 42 weeks, admitted in Sir Salimullah Medical College \& Mitford Hospital for induction of labour. The patient with Previous h/o Ceserean section, Pregnancy with Cardiac disease or asthma and grand multipara were excluded from the study. In a patient , a formal scoring of the cervix was done by pervaginal examination. Those having unfavourable cervix or were not in labour would be selected for induction. In a patient, duration of period after fetal demise was estimated and if exceed fifteen days were excluded from the

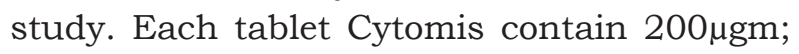
half of a tablet was inserted in the posterior fornix of vagina. Progress of labour was monitored along with close observation. If labour had not been initiated, the same dose was repeated every 6 hours to a maximum of $600 \mu g m$ until adequate contraction was achieved. If cervical dilation did not progress during the active phase, augmentation was done. Intravenous oxytocin was used at-least 4 hours after last dose of misoprostol for augmentation. Induction was considered successful if Bishop's score became favourable (at the time of induction, score was unfavourable) and or /delivery occurs per vaginally with or without augmentation.

\section{Results}

Fifty patients were given induction for labour in between five to twelve days of fetal death.
Youngest patient having intra uterine dead fetus was eighteen years old . Early Ultrasonogram for dating of pregnancy was available in fifteen $(30 \%)$ patients. Date of last menstrual period could be elicited in forty $(80 \%)$ patients. Mean age was $22.12 \pm 4.3$ years.

Table I

Frequency of age of the patient

\begin{tabular}{lcc}
\hline Age in years & Frequency & Percentage \\
\hline $18-24$ & 36 & 72 \\
$25-30$ & 11 & 22 \\
$>30$ & 03 & 06 \\
\hline total & 50 & 100 \\
\hline
\end{tabular}

Table II

Frequency of gestational period

Gestational period Frequency percentage in weeks

\begin{tabular}{lcc}
\hline $28-32$ & 12 & 24 \\
$33-36$ & 22 & 44 \\
$37-40$ & 16 & 32 \\
\hline Total & 50 & 100 \\
\hline
\end{tabular}

Table III

No of patients Induction delivery interval in hrs

\begin{tabular}{lc}
\hline 16 & $8-12 \mathrm{hrs}$ \\
26 & $13-24 \mathrm{hrs}$ \\
08 & $25-48 \mathrm{hrs}$ \\
\hline
\end{tabular}

Mean induction to delivery interval 19.18 6.8 hours

\section{Table-IV}

Induction delivery interval of the patients in relation to Bishops score

\begin{tabular}{lccc}
\hline $\begin{array}{l}\text { Bishops' score } \\
\mathrm{N}=50\end{array}$ & $\begin{array}{c}\text { Number of } \\
\text { individuals }\end{array}$ & $\begin{array}{c}\text { Induction delivery interval } \\
(\text { mean } \pm \mathrm{SD}) \text { in hours }\end{array}$ & $\begin{array}{c}\text { Frequency } \\
(\%)\end{array}$ \\
\hline$<6$ & 41 & $21 \pm 8.25$ & 82 \\
$>6$ & 09 & $10 \pm 1.1$ & 18 \\
\hline
\end{tabular}


Though induction was successful in a thirty three year old lady yet, subsequently LSCS was done due to failure of progress of labor with concomitant Chorioamnionitis

Induction was successful in all patients. Ten patients required Intravenous oxytocin drip (20 units in $1000 \mathrm{ml}$ of Hartman solution). The drop rate was adjusted acccoding to individual need ranging from @10 drops/minute to 40 drops/ minute. Thirty nine patients delivered spontaneously without oxytocin . One patient, third gravida with one living issue and history of two MR had developed fever and other features of chorioamnionities; subsequently LSCS was done.

\section{Discussion}

The use of Prostaglandins in Obstetrics for the termination of pregnancies has undergone a rapid evolution .Prostaglandins have an effect on myometrial contractility, and they also accelerate the physiology of cervical ripening. Induction to delivery time was defined as the time from the initial administration of misoprostol to the complete delivery of the fetus. When $100 \mu \mathrm{gm}$ Misoprostol was inserted into the vagina of 72 women with IUFD at 18-40 weeks pregnancy to induce labour and they inserted another dose every 12 hours upto 48 hours if a patient had not begun labour the mean time between induction of labour to delivery stood at 12.6 hours. ${ }^{8} 92 \%$ delivered within 24 hours while all by 48 hours. ${ }^{8}$ Mean induction delivery interval was found $17 . \pm 6.3$ hours when misoprostol was given at a dose of $400 \mu$ gm at 12 hour interval through vaginal route. ${ }^{8}$ Mean induction delivery interval was found $17.5 \pm 6.3$ hours when misoprostol was given at a dose of $400 \mu \mathrm{gm}$ at 12 hour interval through vaginal route. ${ }^{9}$ This study reveals $93 \%$ expelled within 48 hours where gestational period ranges from 17 weeks to term pregnancy. ${ }^{9}$ Chittacharoen et al found induction delivery interval of $18.87 \pm 10.38$ hours after giving $200 \mathrm{mcg}$ of misoprostol per vaginally in IUFD cases, 67.5 $\%$ deliverd within 24 hours and all were delivered within 48 hours. ${ }^{10}$ In our study 100 $\mu \mathrm{gm}$ was introduced at 6 hour interval and gestational period ranges from 28-40 weeks. Mean induction delivery interval is $19.18 \pm 6.8$ hours.
The plasma concentration of misoprostol in the subjects receiving vaginal doses, rose gradually reaching maximum level between 60 and 120 minutes, declined slowly to an average of $61 \%$ of the peak level at 240 minutes after administration. ${ }^{10} 67.5 \%$ patients deliverd within 24 hours when $200 \mu \mathrm{gm}$ is used per vaginally ${ }^{10}$ In our study $84 \%$ delivered within 24 hours while, all the patients delivered within 48 hours as reported in all other studies. So, induction delivery interval could be shortened by giving higher doses in less frequent interval.

The time between 1st dose and expulsion was significantly lower for women with a Bishop's score of more than 5 than for those with a score of 5 and lower ( 7.6 versus 13.7 hours; $p=.028)^{9}$ .In our study, Patients with Bishops' score more than 6 have induction delivery interval of $10 \pm 1.1$ hours while the value is $21 \pm 8.25$ hours in patients having Bishop's score less than 6 (pd".05). Bishop's score was the only variable associated with time to expulsion.(9)

The reported incidence of vomiting and diarrhoea were $57 \%$ and $29 \%$ respectively in one of the studies on vaginal misoprostol. ${ }^{5}$ The median doses required in that study was $1000 \mu$ gm ${ }^{5}$. In our study two of the patients suffered for nausea vomting of mild degree. None of our patient developed diarrhoea. Using of less dose of misoprostol may explain the low rate of vomiting.

Uterine contraction abnormalities occur with misoprostol, such as hypertonus and hyperstimulation syndrome (contractions lasting longer than 90 seconds or more than five contractions in 10 minutes). ${ }^{11}$. Clinical trial indicate that the optimal dose and dosing interval is $25 \mu$ gm intravaginally every four to six hours. ${ }^{12}$ Higher doses or shorter dosing intervals are associated with a higher incidence of side effects especially hyperstimulation syndrome; Risks also include tachysystole. ${ }^{12}$ In our study, none of the patients developed hyperstimulation syndrome In the third trimester, it is essential to wait for 4 hours or longer after the last misoprostol dose before administering oxytocin to reduce the risk of tachysystole. ${ }^{13}$ In our study, probably low dosing and judicious use of oxytocin was 
responsible for absent hyper stimulation syndrome. Vaginal delivery was $98 \%$ and $2 \%$ needed caesarean section.${ }^{13}$ In our study also $49(98 \%)$ out of 50 patients delivered vaginally and one patient $(2 \%)$ required cesearean section

\section{Conclusion}

Prostaglandins are considered better as the uterus already possesses receptors for prostaglandins. Misoprostol offers an alternative treatment in the management of IUFD besides waiting for spontaneous labour to occur. It is easy to use and can be stored at room temperature.

\section{Limitations of the Study}

Limitations do exist in this study. It could not be carried out in a double-blind way, for obvious reasons which may have caused a bias. Another limitation is that the dose and administration interval were empirical, based on the experience of other authors. It would be better if the result was compared between two group with different does schedule.

\section{Referrences}

1. Maslow AD, Breen TW, Sarna MC, Soni AK, Watkins J, Oriol NE. Prevalence of coagulation abnormalities associated with intrauterine fetal death. Can J Anaesth. 1996 Dec;43(12):1237-43.

2. Nahar S, Rahman A, Nasreen HE. Factors Influencing Stillbirth in Bangladesh: A Case-Control Study. Paediatric and Perinatal Epidemiology. 2013;27(2):158-64.

3. Silver RM, Heuser CC. Stillbirth workup and delivery management. Clin Obstet Gynecol. 2010 Sep;53(3):681-90.

4. Sanchez-Ramos L, Kaunitz AM, Delke I, Gaudier FL. Cervical ripening and labor induction with a controlled-release dinoprostone vaginal insert: a meta-analysis. Obstet Gynecol. 1999 Nov;94(5 Pt 2):878-83.

5. Wong KS, Ngai CSW, Yeo ELK, Tang LCH, Ho PC. A comparison of two regimens of intravaginal misoprostol for termination of second trimester pregnancy: a randomized comparative trial. Human Reproduction. 2000 Mar;15(3):709-12.

6. Harman JJ, Kim A. Current trends in cervical ripening and labor induction. Am Fam Physician. 1999 Aug;60(2):477-84.

7. Wing DA, Lovett K, Paul RH. Disruption of prior uterine incision following misoprostol for labor induction in women with previous cesarean delivery. Obstet Gynecol. 1998 May;91(5 Pt 2):828-30.

8. Bugalho A, Bique C, Machungo F, Faáundes A. Induction of labor with intravaginal misoprostol in intrauterine fetal death. Am J Obstet Gynecol. 1994 Aug;171(2):538-41.

9. Fawole AO, Adekunle AO, Sotiloye OS, Arowojolu AO, Otolorin EO. Experience with intravaginal misoprostol in the management of intra-uterine fetal death. Afr J Med Med Sci. 2004 Jun;33(2):105-8.

10. Chittacharoen A, Herabutya Y, Punyavachira P. A randomized trial of oral and vaginal misoprostol to manage delivery in cases of fetal death. Obstetrics \& Gynecology. 2003 Jan 1;101(1):70-3.

11. Goldberg AB, Greenberg MB, Darney PD. Misoprostol and pregnancy. N Engl J Med. 2001 Jan 4;344(1):3847.

12. Schaff EA, Eisinger SH, Stadalius LS, Franks P, Gore BZ, Poppema S. Low-dose mifepristone $200 \mathrm{mg}$ and vaginal misoprostol for abortion. Contraception. 1999 Jan;59(1):1-6.

13. Easmin S, Nahar K, Jahan MK, Rahim R, Nila TA, Nigar K, et al. Intra-vaginal use of misoprostol for induction of labour in intrauterine death. Mymensingh Med J. 2011 Oct;20(4):566-9. 